\section{"Austerity" in the English National Health Service: fragmentation and commodification - examples not to follow}

\author{
"Austeridade" no Serviço Nacional de Saúde \\ inglês: fragmentação e mercantilização - \\ exemplos para não seguir
}

\author{
"Austeridad" en el Servicio Nacional de Salud \\ inglés: fragmentación y mercantilización - \\ ejemplos a no seguir
}

Lígia Giovanella ${ }^{1}$

In 1997, with Tony Blair's labour government, despite the discourse of a new, more cooperative culture in the public sector and criticism towards competition because increased administrative expenditures and inequalities in access, key elements of the internal market were maintained. The separation of functions remained, but with reorganization that involved the creation of the Primary Care Trust (PCT) as the public administrative agency of the NHS at the local level, responsible for the population's health in its territory. PCTs now managed $80 \%$ of NHS funds for hire public hospitals' specialized services. NHS underfinancing was acknowledged, and government increased public spending in health from $5.3 \%$ of GDP in 2000 to $7 \%$ in 2008 , thereby reducing waiting times and increasing user satisfaction 1,3 .

In the wake of the international financial crisis, beginning in 2010 the conservative-liberal David Cameron government implemented austerity policies to "consolidate" the public budget, centered on spending cuts, including in health ${ }^{4}$. The Health and Social Care Act of 20125 was passed, with the broadest and most dramatic reform of the NHS since its creation in 1948. The law cut 20 billion pounds in spending and aimed to expand free competition and the market by flexibilizing and reducing central control, giving autonomy to local structures led by general practitioners, encouraging competition via 
hiring any qualified provider, public or private, and patients' choice of providers.

The law changed the NHS structure. It extinguished Strategic Health Authorities (SHA) and PCTs, replaced by GP organizations, Clinical Commissioning Groups (CCG), coordinated by a new structure, NHS England, independent of the Department of Health (DoH). It transferred public health responsibilities to local governments and a new organization: Public Health England 4. It expanded the functions of regulatory agencies and determined the transformation of all health establishments in the NHS in foundation trusts (NHS-FT) with broad autonomy and local accountability.

Implementation of the law was complicated, with disorganization resulting from the elimination of previous structures and the creation of new ones, redefinitions, and administrator turnover and reallocation or dismissal of thousands of professionals 6 . The size of the administrative disorganization reflected the transfer of 65 billion pounds to GPs with no experience in hiring services ${ }^{3}$.

Three years since enactment of the law, it is possible to analyze what was implemented and examine the repercussions. A King's Fund report that assessed the reform's implementation as of 2015 highlights the commodification, fragmentation, and disorganization jeopardizing the health system's management and the complexity of the regulatory system 7 .

\section{Fragmentation of the system and de-territorialization}

Rather creating a simpler structure, as argued by the government coalition, the system's reorganization produced a much more complex system with major fragmentation in management and commissioning, fracturing structures and overlapping competencies, producing inefficiencies.

The responsibility of the $\mathrm{DoH}$, the central administration of the NHS operating all across England, was fragmented into many organizations, with supervisory roles over different parts. There is no longer an organization responsible for planning and organizing the healthcare system and health network as a whole 7 . Separation of NHS England from the DoH reduced the state's duty and the responsibility of the Secretary of Health in presenting the NHS accounts, materializing the law that alters the Secretary's duty by replacing "duty to provide care" with "duty to promote care" 8,9 .
New regulatory agencies with overlapping roles made the regulatory system confusing and prone to flaws, with repercussions on quality 7 .

Responsibility for commissioning was fragmented between NHS England, CCGs, support units for commissioning (some of which are partnerships with private insurance companies and consulting firms) 10, and local governments, responsible for hiring public health services.

Fragmentation of commissioning leads to hiring of different providers for care and treatment of the same condition. It affects continuity of care and results in insufficient coordination between specialized primary and tertiary care and between public health programs and individual care.

Shifting public health responsibilities to local governments introduced a dichotomy between individual and collective care. This and the fact that CCGs are only responsible for the patients on their own lists leads to loss of territorial perspective and population-based planning and budgeting 9 .

Purchasers and providers competing in the market do not follow territorial limits. Territorial organization with regionalized supply of secondary services is dismantled, and the population perspective fades. Competition can lead to hiring services in any geographic area and requires that providers establish numerous contracts to serve patients from different CCGs, with an increase in administrative and transportation expenses.

\section{Commodification}

A wide range of authors agree that the law increased the commodification of the NHS 3,7,8, expressed as expanded competition among providers and patients' choice, new management formats in public establishments, managerialism, incentives for purchase of private services, privatization of Commissioning Support Units (CSU), and services by tender for private operator franchises and personalized budgets for continuing care.

Healthcare remains publically financed, but to be provided in a competitive market by commissioning any qualified provider. The CCGs' mandatory offer of provider options to patients expands competition, and the private market associates personalization of care with patients' responsibility 11 .

The law has also incentivized an increase in purchase of services in the private sector, but the proportion of NHS spending on private 
providers remains low. In 2007-2008 such spending was $6.4 \% 1$ of the NHS annual budget, increasing in 2013-2014 to $9.3 \%$ of the annual budget of 102.6 billion pounds 12 . According to estimates, $40 \%$ of the resources from tenders in 2014 were for hiring private services 12 . The largest increases in private participation were among community health services providers, from $20 \%$ in 2011-2012 to $31 \%$ in $2013-2014$. Meanwhile, purchase of private services in the hospital sector remained small at $4 \% 13$.

The new legal format of foundation trusts (NHS-FT) means commodification: in order to survive competition, trusts must raise funds from other sources and offer what they consider profitable, with provision controlled merely by minimum quality standards, divorced from the population's health needs 14 . Private interests and the private ethos become interwoven with public services, with NHS administrators increasingly coming from the private sector to replace career civil servants, abandoning the public ethos for commercial ethos, to the detriment of patients' interests ${ }^{14}$. Meanwhile, the NHS-FT model appears to have exhausted its potential, due to repeated financial difficulties and quality problems 7,12,15.

Budgetcuts of 15billion poundshavenegatively impacted quality 12 , increased waiting time 16, and reduced patient satisfaction 17. Persistent financial difficulties, budget deficits, quality problems, poor management, high debts in publicprivate partnerships for infrastructure financing, and staff shortages in health services have become frequent problems 7,12,15.

Contrary to prognostication by the conservative-liberal coalition, commodification and fragmentation have produced inefficiencies and major administrative spending hikes (from $6 \%$ to $15 \%$ ) because multimillion-pound tenders, mergers, and hiring of private consultancies 7 . According to one estimate, the NHS costs 19 billion pounds to function as a market.

Meanwhile, the system has not undergone privatization of financing. Healthcare is still financed with public resources, predominantly taxes. Public spending in health in 2013 accounted for $85 \%$ of all health spending and represented $7.3 \%$ of GDP, with little variation in recent years 4,18 .

\section{Summary}

Authors agree that the conservative-liberal reform increased the commodification and fragmentation of the NHS, but has still not led to wholesale privatization. Patients' daily experience with use of the system has not changed substantially thus far, due at least partly to the commitment of public servants suffering from the intended changes 3 .

There is no evidence that the new arrangement, with separation of procurement and provision, is more effective in improving quality of services, nor that competition produces efficiency to compensate for the resulting increase in transaction costs 7 .

The reform extends previous initiatives. Commodification of the NHS originated in the Thatcher administration, opening the system to the market. The process continued with New Labour, reorganizing the internal market, expanding regulation, and paving the way for the conservative-liberal coalition to open the doors to the market: from an "internal market" to an unmanaged "external market".

This insidious and continuous commodification muddles the borders between public and private 19 and threatens both the sustainability of the NHS as a comprehensive universal public system and the guarantee of the right to health 4,8 .

Implementation of any policy entails changes influenced by the legacy of previous policies, stakeholder pressure, necessary negotiations, and action by policy implementers in management and frontline healthcare provision. The reform is still under way, and this may be one more episode (albeit a very important one) in a gradual process of changes in the NHS which transformed its structure, but which kept the service faithful to its mission, according to Klein 3 .

The NHS is still financed by taxes, and the system provides universal access, usually with no payment at the time of use (except for medicines). It has apparently survived as a national treasure. But will it continue to be? 
1. Boyle S. United Kingdom (England): health system review. Health Syst Transit 2011; 13:1-483.

2. Davis K, Stremikis K, Squires AD, Schoen C. Mirror, mirror on the wall: how the performance of the U.S. health care system compares internationally. 2014 Update. New York: The Commonwealth Fund; 2014.

3. Klein R. The new politics of the NHS: from creation

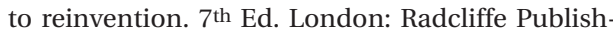
ing; 2013.

4. Giovanella G, Stegmüller K. The financial crisis and health care systems in Europe: universal care under threat? Trends in health sector reforms in Germany, the United Kingdom, and Spain. Cad Saúde Pública 2014; 30:2263-81.

5. United Kingdom. Health and Social Care Act 2012. http://www.legislation.gov.uk/ukpga/2012/7/con tents/enacted (accessed on 02/Aug/2012).

6. Campbell D. 7,000 key NHS clinical staff made redundant amid enforced cuts. The Guardian 2013; 31 dec.

7. Ham C, Baird B, Gregory S, Jabbal J, Alderwick H. The NHS under the coalition government. Part one: NHS reform. London: The King's Fund; 2015.

8. Pollock A, Roderick P. Duty to care and universal access to health: in defence of a duty to care and provide universal access to health in the face of limited resources. Med Leg J 2015; 83:172-84.

9. Pollock A, Price D. How the secretary of state for health proposes to abolish the NHS in England. BMJ 2011; 342:d1695.
10. NHS England. NHS England launches new framework for commissioning support services. https:// www.england.nhs.uk/2015/02/lpf-launch/ (accessed on 06/Mar/2016).

11. Sheppard MK. Fallacy or functionality: law and policy of patient treatment choice in the NHS. Health Care Anal 2014; [Epub ahead of print].

12. El-Gingihy Y. The NHS is on a one-way road to privatization. The Guardian 2015; 2 feb.

13. Lafond S, Arora S, Charlesworth A, McKeon A. Into the red? The state of the NHS' finances. An analysis of NHS expenditure between 2010 and 2014. London: Nuffield Trust; 2014.

14. Leys C, Player S. The plot against the NHS. Pontypool: The Merlin Press; 2011.

15. This is the NHS project. The Guardian 2016; 5 feb.

16. Appleby J, Baird B, Thompson J, Jabbal J. The NHS under the coalition government. Part two: NHS performance. London: The King's Fund; 2015.

17. Appleby J, Robertson R. Public satisfaction with the NHS in 2015. http://www.kingsfund.org.uk/ projects/public-satisfaction-nhs/bsa-survey-2015

18. Organisation for Economic Co-operation and Development. OECD Health Data 2015. http://stats. oecd.org / index.aspx? DataSetCode=HEALTH STAT\# (accessed on 07/Mar/2016).

19. Hunter DJ. The slow, lingering death of the English NHS. Commentary. Int J Health Policy Manag 2016; 5:55-7. 